Journal of Engineering Sciences, Assiut University, Vol. 40, No 2, pp.419-432, March 2012

\title{
DESIGN AND EVALUATION OF DIFFERENT DEVICES FOR MEASURING AIR DRY-BULB TEMPERATURE IN A FOGGY ENVIRONMENT
}

\section{A. N. Shmroukh, I. M. S. Taha, A. M. Abdel-Ghany and M. Attalla}

\author{
(Received June 5, 2011 Accepted November 28, 2011)
}

Fogging system has been widely used for cooling and humidification applications such as in greenhouses, cooling towers, factories and conditioning systems. However, measuring the correct air dry bulb temperature by using the conventional psychrometer under a foggy environment may include a significant underestimation error. This is because of the fog wafts in the air introduced to the psychrometer. If the fog adheres to the junction of the thermocouple, measurement of dry bulb temperature is underestimated and sometimes indicates the wet bulb temperature if the fog evaporates. The present study focuses on increasing the accuracy of air dry bulb temperature under the fogging condition. Such estimation is accomplished by equipping the thermocouple junctions with different devices designed mainly to separate the non-evaporated fog before reaching the junction. The proposed devices are: gravity settler, truncated square pyramid, cyclone and cylindrical sudden enlargement. Such devices are experimented in a plexi glass (acrylic) covered box exposed to different values of fogging on-off duration and fogging rate. Air dry bulb temperature is measured by using the proposed devices are compared with free junction positioned in the acrylic covered box and with the conventional psychrometrer device. The results show that the proposed devices improve the measured air dry bulb temperature toward the correct value over that of the free junction. Putting in order: Cyclone device it is found that is better, followed by cylindrical enlargement device, gravity settler and truncated square pyramid. They respectively increased the temperature measured by the free junction in the range from 2.2 to $4.01 C$, 1.97 to $3.62 \mathrm{C}, 1.89$ to $3.52 \mathrm{C}$ and from 1.77 to $3.34 \mathrm{C}$ for different fog onoff duration.

KEYWORDS: Temperature measurements, dry bulb temperature, water droplets separators.
$\mathrm{C}_{\mathrm{D}} \quad$ Drag coefficient
$\mathrm{D}_{\mathrm{p}} \quad$ Particle diameter, $\mathrm{m}$
Diameter at which the particle
$D_{t} \quad$ suspension occurs, $m$
g Acceleration of gravity, $\mathrm{m} / \mathrm{s}^{2}$
$\mathrm{H}_{\mathrm{s}} \quad$ Gravity settler height, $\mathrm{m}$

\section{List of symbols}

$\mathrm{T}_{\mathrm{w}} \quad$ Wet bulb temperature, ${ }^{\circ} \mathrm{C}$

$\mathrm{u}$ Relative velocity between particle and fluid $\left(\mathrm{v}_{\mathrm{asp}}-\mathrm{v}_{\mathrm{t}}\right), \mathrm{m} / \mathrm{s}$

Air velocity in gravity settler inlet,

$\mathrm{v}_{\mathrm{g}} \mathrm{m} / \mathrm{s}$

$\mathrm{v}_{\mathrm{t}} \quad$ Terminal settling velocity, $\mathrm{m} / \mathrm{s}$

$\mathrm{v}_{\text {asp }}$ Aspiration velocity, $\mathrm{m} / \mathrm{s}$ 


\begin{tabular}{|c|c|c|c|}
\hline $\begin{array}{l}\mathrm{L}_{\mathrm{s}} \\
\mathrm{Q}\end{array}$ & $\begin{array}{l}\text { Gravity settler length, } \mathrm{m} \\
\text { air flow rate, } \mathrm{m}^{3} / \mathrm{s}\end{array}$ & $\mathrm{W}_{\mathrm{s}}$ & Gravity settler width, $\mathrm{m}$ \\
\hline & Particles' Revnolds number & $\mu_{\mathrm{f}}$ & A1r viscosity, Ps.s \\
\hline $\operatorname{Re}_{\mathrm{p}}$ & $\left(D_{p} \rho_{f} u / \mu_{f}\right)$ & $\rho_{\mathrm{f}}$ & Air density, $\mathrm{kg} / \mathrm{m}^{3}$ \\
\hline $\mathrm{T}_{\mathrm{d}}$ & Dry bulb temperature, ${ }^{\circ} \mathrm{C}$ & $\rho_{\mathrm{p}}$ & Particle density, $\mathrm{kg} / \mathrm{m}^{3}$ \\
\hline
\end{tabular}

\section{INTRODUCTION}

Fog systems for cooling or humidification have been examined for over 20 years in terms of cooling performance [H. Toida]. The application of the fog system is still limited, although the fog system requires less initial cost compared with that of other cooling systems such as pad-and-fan systems. A possible reason for its limited use is poor control results, which sometimes results in undesirable air temperature and relative humidity inside the space which have been cooled or humidified. Air dry bulb temperature is essentially needed as an input parameter to any control system. Thus, the air dry-bulb temperature in the space needs to be measured accurately. During the operation of the fog system, certain amount of fog evaporates reducing the air temperature but the remainder is not evaporated. The non-evaporated fog wafts in the air inside the medium. If the un-evaporated fog adheres to the sensing part of the thermometer, the value of dry bulb temperature decreases, and sometimes reaches the wet bulb temperature in case the fog evaporates. Until now, an aspirated psychrometer (conventional device) is commonly used to measure the air temperature in greenhouses and fields [H. Toida], because of its nominal accuracy and simplicity. However, the fog adhering to the sensing part of the thermometer causes an underestimation of the value of dry bulb temperature during the operation of the fog system. The objective of this study is to establish a more accurate method to determine dry bulb temperature during the operation of the fog system. To prevent the un-evaporated fog adhering to the sensing part of the thermometer, different separating devices as cyclone separator, sudden enlargement separators and gravity settler are designed and used compared with a conventional shielded device and a free thermocouple junction for measuring of dry bulb temperature during the operation of the fog system.

Reviewing the literature revealed that few papers have reported a study on the effect of the fogging in greenhouse cooling or any other application in the temperature measurement. Moreover, only one experimental work [H. Toida] has been performed to study the effect of the fog on the air dry bulb temperature measurement.

$\mathrm{Y}$. Li et al. developed a new temperature measuring system for gas-liquid flow in sprayed field. Their system composed of shielded and unshielded thermocouples, a copper mesh for eliminating the droplets in the two phase flow. The thermocouple outside the shield was for measuring the liquid droplets temperature and the thermocouple inside the shield was for measuring the gas temperature after preventing the droplets from entering the shield. The proposed system is complex and costly because of using many (200) meshes and vacuum pump.

In $2006 \mathrm{H}$. Toida et al. examined three different configurations of thermometers used for measuring the air dry bulb temperature in a single-span glass greenhouse cooled by a fogging system. Fog wafts in the air inside the greenhouse, and the measured dry bulb temperature sometimes reaches the air wet-bulb temperature. 
The first thermometer configuration used by [H. Toida] was the non-aspirated sensor "NS", which consisted of a column-shaped shelter. A copper-constantan thermocouple (T-type thermocouple rounded by water sensitive papers) was installed at the centre of the shelter. The flat roof held to prevent the fog from entering the shelter. The second configuration used by [H. Toida] was a conventional aspirated psychrometer "AS ". A copper-constantan thermocouple was installed in the pipe at a certain distance from the air intake. The third configuration used by [H. Toida] was a non- aspirated bare sensor without the shelter (free junction) "NN". Their results showed that the non aspirated thermocouple NS in a column-shaped shelter with a flat roof produces a higher air dry bulb temperature $\left(\mathrm{T}_{\mathrm{d}}\right)$ than the conventional aspirated psychrometer and also higher than the non-aspirated bare sensor without shelter NN. In their study [H. Toida], the measurements of dry bulb temperature were not accurate because the air was stagnant which caused energy accumulation. For accurate measurements of dry bulb temperature, air must be movable. Finally, fog was not separated off the sensor causing error in the measured dry bulb temperature.

The objective of the present work is to design, construct and experimentally examine different devices for measuring the air dry bulb temperature after the separation process. Another reference device is used for measuring the air temperature without separation. A comparative study is done to reach better device which leads to more accurate measurement of air dry bulb temperature.

\section{EXPERIMENTAL SETUP}

The experiments are carried out in a Plexiglas box $(0.7 \mathrm{~m}$ wide, $0.7 \mathrm{~m}$ long, $0.8 \mathrm{~m}$ high) as shown in Fig.1. The box is equipped with a fog system consisting of a nozzle with its water tank jointed with an air compressor of 10.5 bar maximum storage pressure by a $4 \mathrm{~m}$ high pressure line for generating fog and the average droplet size of fog is about $50 \mu \mathrm{m}$. The fans of the devices, used to drawing air to the temperature measuring section, are connected in parallel to a DC power supply for producing a constant voltage drop on each fan of $12 \mathrm{~V}$ and for producing a current up to $100 \mathrm{~mA}$. The air dry bulb temperature has been measured by using 6 type-K thermocouple (Chromel, Alumel) probes. The voltage output is connected with a data acquisition device having 8 channels with a maximum error of $\pm 0.691 \mathrm{C}$, connected to a computer for exiting the measured temperature data of the five devices and the free junction in the box at the same time.

The six thermocouples used to measure the air dry bulb temperature are calibrated at three constant temperature conditions which are the water boiling, an alcohol boiling and an ice-water mixture against a glass tube alcohol thermometer with $-10^{\circ} \mathrm{C}$ to $110^{\circ} \mathrm{C}$ temperature range. All thermocouples are connected to the data acquisition device to calibrate the thermocouples and the acquisition device.

\section{Cyclone Separator Device}

Nowadays hydrocyclones are used for gas-liquid separation [L. F. Mart'inez]. Also they have a larger conical part length than its cylindrical part length which gives high efficiency [B. Wang]. In the present study the cyclone separator dimensions are selected based on the Rietema hydrocyclone design data reported in [L.R. Castilho, B. Wang] for designing the hydrocyclones as shown in Fig.2 .The air-water droplets 
mixture enters a cyclone tangentially to the upper cylindrical shell as shown in Fig.2. By the centrifugal force action the heavier droplets move towards the wall and then move downward and are accumulated from the lower exit pipe. Air with the remaining small droplets move inward and then upward through the exit upper pipe to the thermocouple section then discharged by the fan at $3.5 \times 10^{-3} \mathrm{~m}^{3} / \mathrm{s}$ flow rate to the container (acrylic box).

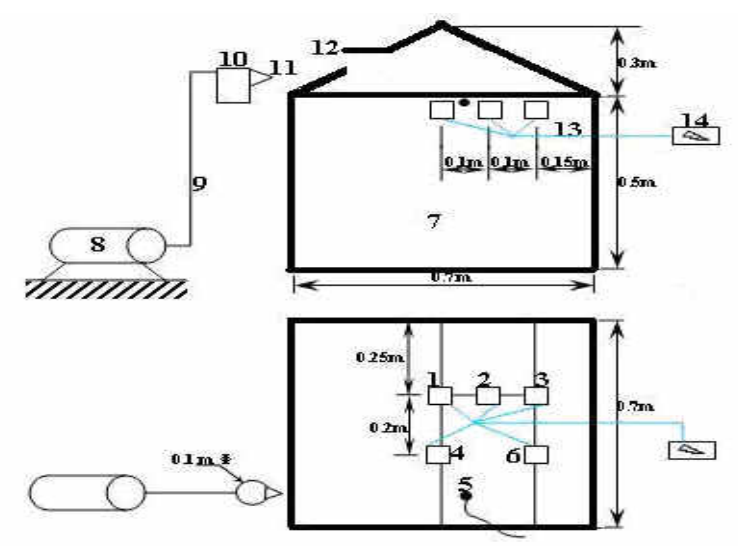

(1) Conventional shielded type device, (2) gravity settler, (3) Truncated square pyramid enlargement, (4) cylindrical enlargement, (5) free junction, (6) cyclone, (7) acrylic box, (8) compressor, (9) high pressure line, (10) water tank, (11) water nozzle,

(12) fogging window, (13) fan power lines, (14) DC power supply

Fig. 1 Layout dimensions and measuring locations in the acrylic box used in the experiments.

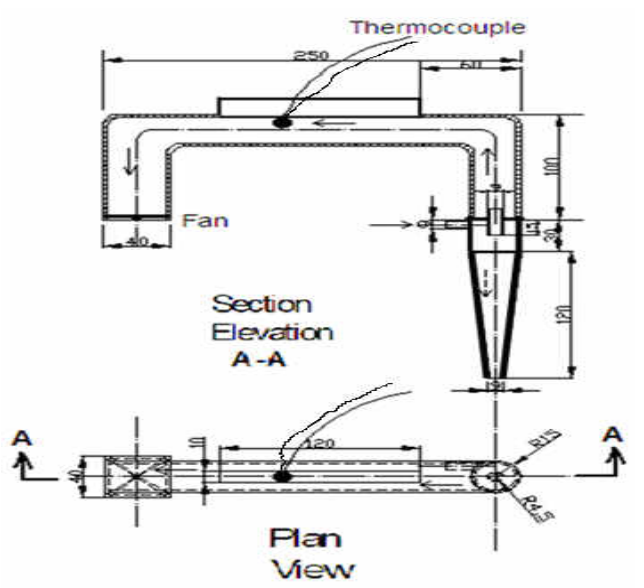

Fig. 2 Cyclone separator device. $\rightarrow$ Water droplets path, Air or Air-Water droplets mixture path, dimensions in $\mathrm{mm}$. 


\section{The Variable Area Devices (Truncated Square Pyramid And Cylindrical Sudden Enlargement)}

The air-water droplets mixture enters the truncated square pyramid or the cylindrical enlargement device from its lower opening as shown in Fig 3 and Fig 4. For both devices, the separation action occurs due to the decrease of air velocity to a value lower than the settling velocity of the water droplets of a certain diameter. Thus, water droplets having diameters larger than that for the air pre-designed velocity in the enlarged section, are settled down. The air then passes through the exit pipe attached to the upper part of cylindrical and truncated square pyramid section. It is then passed to the location of the thermocouple junction in the device, and discharged to the acrylic box by the fan. The air flow rate of the fan is also $3.5 \times 10^{-3} \mathrm{~m}^{3} / \mathrm{s}$.

The calculations needed for the design of the enlargement section are presented as follows [R. H. Perry]:

The terminal velocity $\mathrm{v}_{\mathrm{t}}$ of the droplets is given by

$\mathrm{v}_{\mathrm{t}}=\sqrt{\left(\left(4 g D_{p}\left(\rho_{f}-\rho_{p}\right) /\left(3 \rho_{f} C_{D}\right)\right)\right.}$,

where $\mathrm{C}_{\mathrm{D}}$ is the drag coefficient and is given by

$\mathrm{C}_{\mathrm{D}}=\left(24 / \mathrm{Re}_{\mathrm{p}}\right) \mathrm{x}\left(1+0.14 \mathrm{Re}_{\mathrm{p}}{ }^{0.7}\right)$

The particle diameter $\mathrm{D}_{\mathrm{p}}=50 \mu \mathrm{m}$ (The minimum diameter assumed to be separated), $\mathrm{g}$ is the acceleration of gravity, $\rho_{\mathrm{f}}$ is the air density $\left(=1.2 \mathrm{~kg} / \mathrm{m}^{3}\right), \rho_{\mathrm{p}}$ is the droplet density $\left(=1000 \mathrm{~kg} / \mathrm{m}^{3}\right)$ and $\mathrm{Re}_{\mathrm{p}}$ is the droplets Reynolds number given by

$\operatorname{Re}_{\mathrm{p}}=\left(D_{p} \rho_{f} u / \mu_{f}\right), \quad 0.1<\operatorname{Re}_{\mathrm{p}}<1000$,

$\mathrm{u}=\left(\mathrm{v}_{\mathrm{asp}}-\mathrm{v}_{\mathrm{t}}\right)$ is the relative velocity between droplet and air and $\mu_{\mathrm{f}}$ is the air viscosity $\left(=1.81 \times 10^{-5}\right.$ pa.s $)$.

For a mixture flow rate $\mathrm{Q}=3.5^{\times} \times 10^{-3} \mathrm{~m}^{3} / \mathrm{s}$ and a pipe diameter $\mathrm{D}_{\text {pipe }}=30 \mathrm{~mm}$, the aspiration velocity is $\mathrm{v}_{\text {asp }}=4.9 \mathrm{~m} / \mathrm{s}$. An iteration method is then used to obtain the value of $v_{t}$ using Eqs. (1) and (2). Its value is obtained to be $0.425 \mathrm{~m} / \mathrm{s}$. Thus the diameter at which the separation occurs is $\mathrm{D}_{\mathrm{t}}=102 \mathrm{~mm}$.

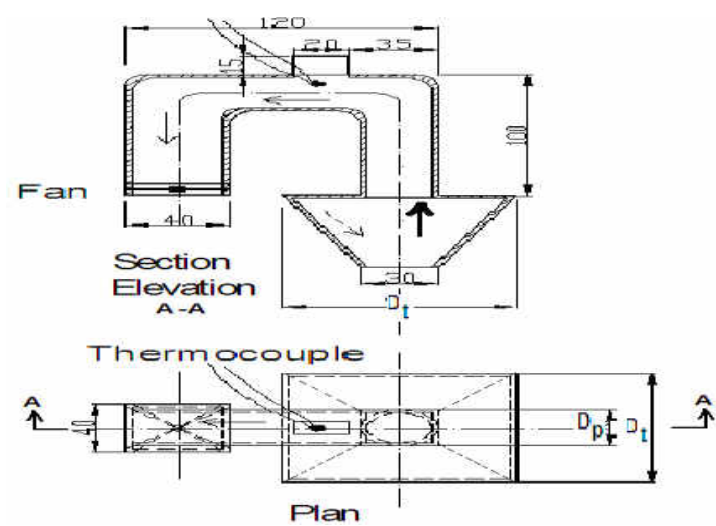

Fig. 3 Truncated square pyramid enlargement device.

Water droplets path,

$\rightarrow$ Air or Air-Water droplets mixture Path, all dimensions in mm 


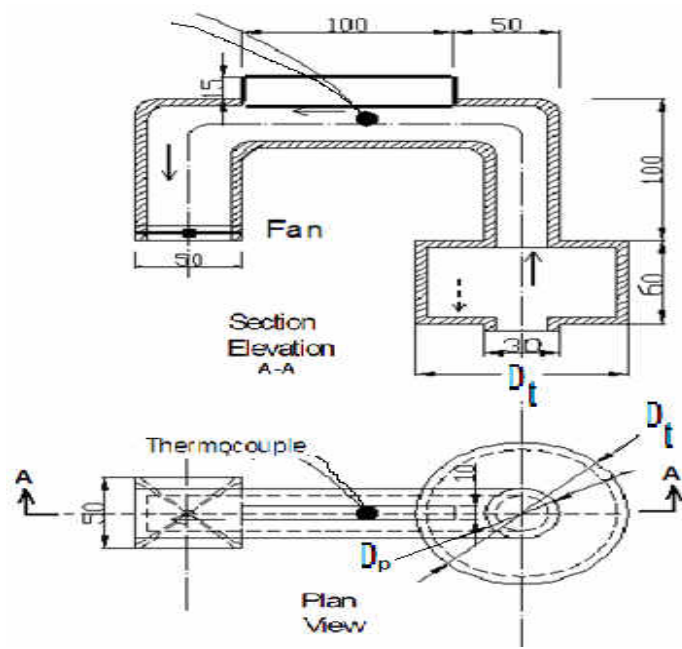

Fig. 4 Cylindrical sudden enlargement device:

$\rightarrow$ Water droplets path, Air or Air-Water droplets mixture Path, all dimensions in mm

\section{Gravity Settler Separator Device}

In the gravity settler Fig.5, the air-water droplets mixture is drawn at a rate of $1.75 \times 10^{-3} \mathrm{~m}^{3} / \mathrm{s}$ by a fan through an inlet pipe to the rectangular box gravity settler via an opening at the center of the front of the rectangular box. The mixture passes in the box with a reduced velocity causing water droplets to fall to the bottom of the rectangular box by the gravity action. Then, the air passes upward through the upper pipe attached to the upper surface of the box at its end to the thermocouple junction section. Air with any remaining water droplets is then passed through the fan section to the acrylic box.

The equation relating minimum particle diameter to the air discharge and settler dimensions (width Ws and length Ls) is:

$\mathrm{D}_{\mathrm{p}}=\sqrt{\left(\left(18 Q \mu_{f}\right) /\left(g W_{s} L_{s}\left(\rho_{p}-\rho_{f}\right)\right)\right.}$

$\mathrm{Q}=\mathrm{v}_{\mathrm{g}} \mathrm{H} \mathrm{W}_{\mathrm{s}}$

For air at $20^{\circ} \mathrm{C}$ and atmospheric pressure, water minimum particle diameter of $\mathrm{D}_{\mathrm{p}}=50 \mu \mathrm{m} \mathrm{Eq(4)}$ gives a value for $\mathrm{W}_{\mathrm{s}}$ multiplied by $\mathrm{L}_{\mathrm{s}}$ of $0.023 \mathrm{~m}^{2}$. For a chosen value of $\mathrm{L}_{\mathrm{s}}$ of $0.15 \mathrm{~m}$, the value of $\mathrm{W}_{\mathrm{s}}$ is then $0.153 \mathrm{~m}$. For a pipe diameter $\mathrm{D}_{\text {pipe }}$ of $30 \mathrm{~mm}$, the gas velocity leaving the settler $\mathrm{v}_{\mathrm{g}}$ is $0.376 \mathrm{~m} / \mathrm{s}$ and Equ. (5) predicts the value of $0.03 \mathrm{~m}$ for the gravity settler height $\mathrm{H}_{\mathrm{s}}$.

\section{Conventional shielded (Reference) device}

To compare the results of air dry bulb temperature $\mathrm{T}_{\mathrm{db}}$ for different devices with that measured without separation of water droplets a reference design was made. Air-fog droplets mixture is drawn by a fan at a rate of $3.5 \times 10^{-3} \mathrm{~m}^{3} / \mathrm{s}$ to a horizontal pipe followed by a vertical pipe. The thermocouple is positioned at the center of the horizontal pipe as shown in Fig. 6. 


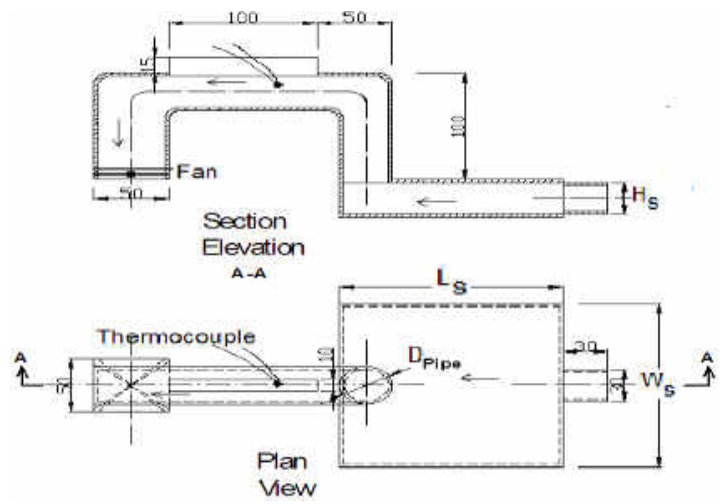

Fig. 5 Gravity settler device.

$\rightarrow$ Water droplets path, Air or Air-Water droplets mixture Path, all dimensions in $\mathrm{mm}$

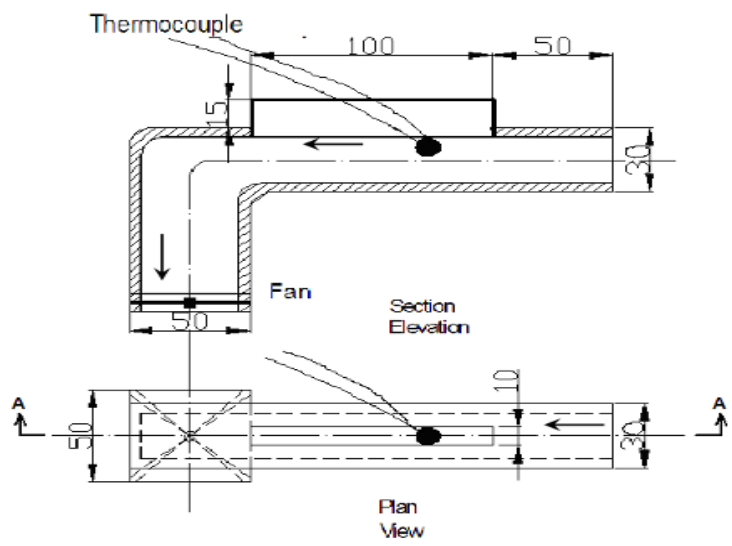

Fig. 6 Conventional shielded type device. $\rightarrow$ Water droplets path, Air or

Air-Water droplets mixture Path, all dimensions in mm

\section{EXPERIMENTAL PROCEDURE}

The numbers of performed experiments are twelve. Each experiment has different conditions, the effect of the following parameters on the measured temperature in different devices are: (1) fogging rate with three values of $0.1 \mathrm{l} / \mathrm{min}, 0.033 \mathrm{l} / \mathrm{min}$ and $0.022 \mathrm{l} / \mathrm{min}$, (2) fogging duration which has multiple modes of (cyclic $4 \mathrm{~min}$ fog-on followed by $4 \mathrm{~min}$ fog-off, cyclic $3 \mathrm{~min}$ fog-on followed by $3 \mathrm{~min}$ fog-off, continuous fogging, $10 \mathrm{~min}$ fog-on followed by $3 \mathrm{~min}$ fog-off then fog-on to steady state condition, $15 \mathrm{~min}$ fog-on followed by $5 \mathrm{~min}$ fog-off then fog-on till reaching steady state.

The initial temperature changed from one experiment to another as can be detected in following figures. The conditions chosen simulate the actual conditions in greenhouses where the on-off control of the fogging procedure simulates the temperature control in the greenhouse or any other space needed to be cooled.

The experiment steps changed with the experiment mode as follows. For experiments having a fog-on followed by a fog-off the experiment started by opening 
the pressurized air delivery valve and the nozzle port. Then after a prescribed time the fog stopped by closing the pressurized air delivery valve and the nozzle port, and repeating the process. The measured data from each device and from free junction are monitored each minute to the specified time. For the other experiments where only fogon mode is applied, the same procedure for applying the fog is done and continued till reaching the steady state condition.

\section{RESULTS AND DISCUSSION}

\section{Effect of Fog Flow Rate}

Figures 7 to 9 show the time variation of the measured air dry bulb temperature by free and devices junctions with fog-on for 10 min followed by 3 min fog-off followed by fog-on to steady state mode with fog flow rate of $0.022 \mathrm{l} / \mathrm{min}, 0.033 \mathrm{l} / \mathrm{min}$ and 0.1 $1 /$ min respectively. The air temperature inside the cyclone device is greater than any other device, the performance of other devices in descending order is that of the cylindrical enlargement device, the gravity settler, the truncated square pyramid enlargement device and finally the conventional shielded type device which give a temperature reading close to the previous devices. The free junction had the lowest air temperature which is expected because the fog is in contact with the thermocouple sensor. Increasing the fog flow rate, makes the temperature in the cyclone device more close to the other devices, the maximum temperature difference between the cyclone device and the cylindrical device reached $0.9 \mathrm{C}$ but between the cyclone device and the free junction the difference reached $4.3 \mathrm{C}$.

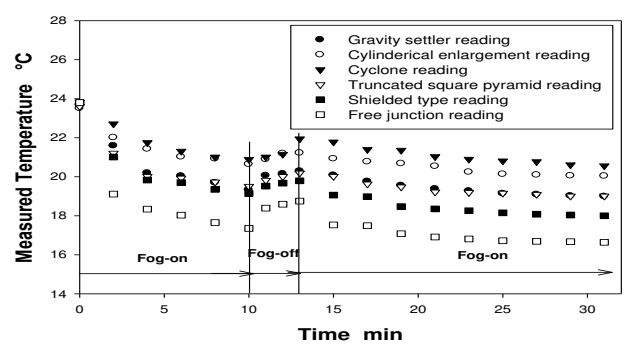

Fig. 7 Comparison between the measured air dry bulb temperature by the devices and the free junction in the glass box at $10 \mathrm{~min}$ fog-on, $3 \mathrm{~min}$ fog-off, fog-on to steady state, with $0.022 \mathrm{l} / \mathrm{min}$ fog rate.

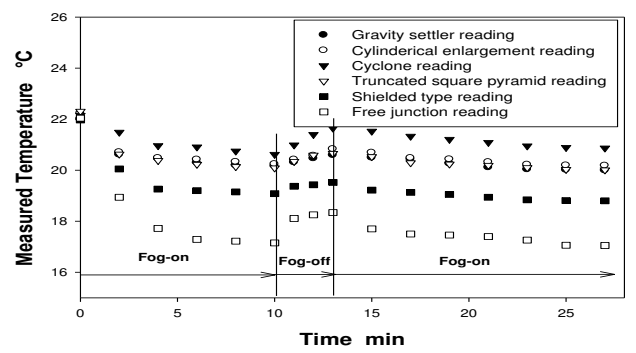

Fig. 8 Comparison between the measured air dry bulb temperature by the devices and the free junction in the glass box at $10 \mathrm{~min}$ fog-on, $3 \mathrm{~min}$ fog-off, fog-on to steady state, with $0.033 \mathrm{l} / \mathrm{min}$ fog rate. 


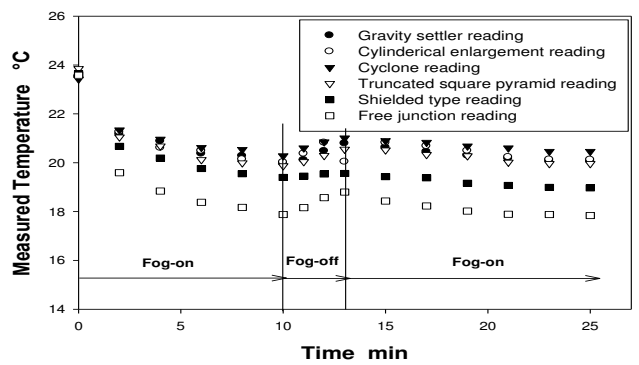

Fig. 9 Comparison between the measured air dry bulb temperature by the devices and the free junction in the glass box at $10 \mathrm{~min}$ fog-on, 3 min fog-off, fog-on to steady state, with $0.1 \mathrm{l} / \mathrm{min}$ fog rate.

\section{Effect of Increasing Fog-On and Fog-Off Periods}

Figures 10 to 12 illustrate the measured air dry bulb temperatures with increasing the fog-on time to be $15 \mathrm{~min}$ and increasing the fog-off time to be $5 \mathrm{~min}$ with $0.022 \mathrm{l} / \mathrm{min}$, $0.033 \mathrm{l} / \mathrm{min}$ and $0.1 \mathrm{l} / \mathrm{min}$ fog flow rate respectively. During the fog-on period, the measured air temperature decreased with time for all devices. The air temperature inside the cyclone device was greater than any other device, the performance of other devices in descending order is that of the cylindrical enlargement device, the gravity settler, the truncated square pyramid enlargement device and finally the conventional shielded type device which give a temperature reading close to the previous devices. The free junction had the lowest air temperature which is expected because the fog is in contact with the thermocouple sensor. Under fog-off period all of the air temperatures increased in all devices as the fog density existing in the air stopped increasing. The temperature in the cyclone device is still greater than that in the other devices. The free junction always has the lowest air temperature. For the same fog rate the maximum difference between the temperature reading of the cyclone device and the free junction in the latter $15 \mathrm{~min}$ fog-on experiments is slightly higher than in the first $10 \mathrm{~min}$ fog-on. That increase in temperature difference appeared because the rate of decreasing the free junction temperature is more than the rate of decreasing devices temperature (specially the cyclone). The sprayed fog which increased in the space during the fog-on period and touched the free junction is probably the reason of decreasing the free junction temperature with a high rate for the same fog rate, the maximum temperature difference between the cyclone device and the cylindrical device reached $1.2 \mathrm{C}$ and the maximum difference between the cyclone device and the free junction reaches $3.6 \mathrm{C}$.

\section{Effect of Cyclic Fog-On and Fog-Off}

Figures 13 to 15 indicate the relation between the measured air dry bulb temperature by free and devices junctions under cyclic 4 min fog-on then 4 min fog-off mode with fog flow rate of $0.022 \mathrm{l} / \mathrm{min}, 0.033 \mathrm{l} / \mathrm{min}$ and $0.1 \mathrm{l} / \mathrm{min}$ respectively. Under the $4 \mathrm{~min}$ fogon period the air temperature decreased and the air temperature inside the cyclone device is greater than any other device as for all other experiments. The performance of the other devices in descending order is that of the cylindrical enlargement device, the 
gravity settler, the truncated square pyramid enlargement device, the conventional shielded device and finally the free junction which has the lowest air temperature. However, under the 4 min fog-off period the air temperature increased in all devices. The free junction always has the lowest air temperature and so on in the remaining period of fog-on and fog-off modes. The data also shows that the maximum temperature difference between the cyclone device and the cylindrical device reached $1.8 \mathrm{C}$ but between the cyclone device and the free junction the difference reached $4.5 \mathrm{C}$.

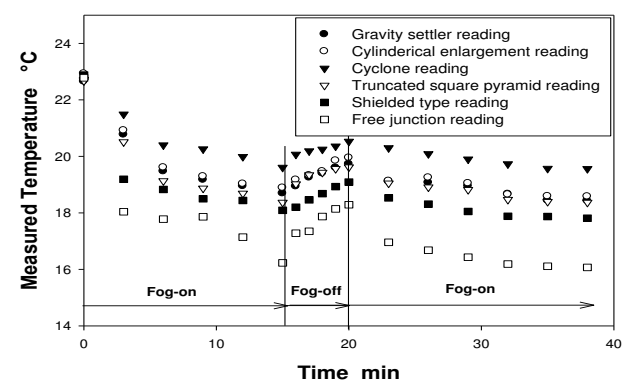

Fig.10 Comparison between the measured air dry bulb temperature by the devices and the free junction in the glass box at $15 \mathrm{~min}$ fog-on, $5 \mathrm{~min}$ fog-off, fog-on to steady state, with $0.022 \mathrm{l} / \mathrm{min}$ fog rate.

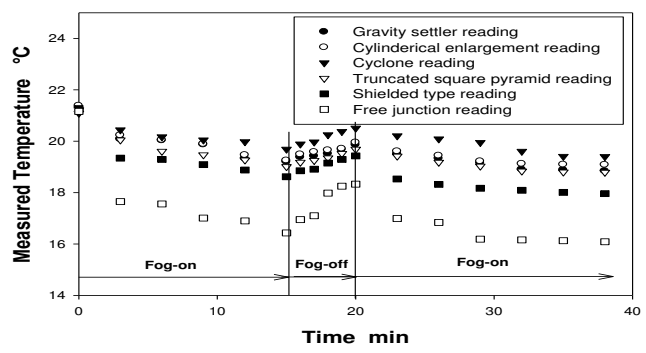

Fig. 11 Comparison between the measured air dry bulb temperature by the devices and the free junction in the glass box at $15 \mathrm{~min}$ fog-on, $5 \mathrm{~min}$ fog-off, fog-on to steady state, with $0.033 \mathrm{l} / \mathrm{min}$ fog rate.

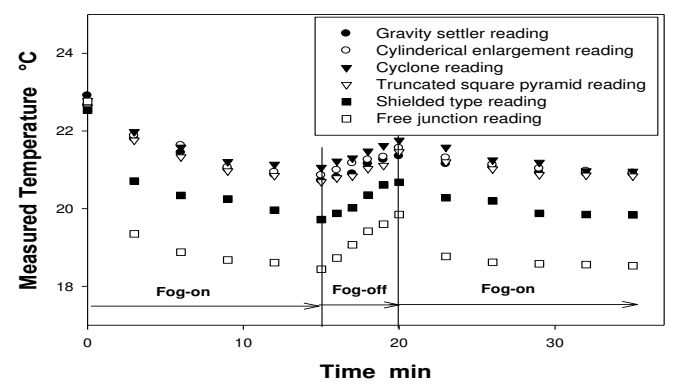

Fig.12 Comparison between the measured air dry bulb temperature by the devices and the free junction in the glass box at $15 \mathrm{~min}$ fog-on, $5 \mathrm{~min}$ fog-off, fog-on to steady state, with $0.1 \mathrm{l} / \mathrm{min}$ fog rate. 


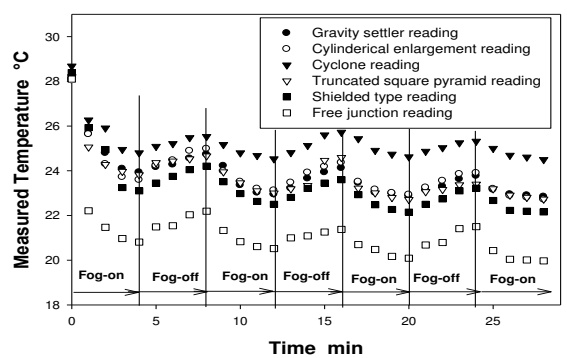

Fig.13 Comparison between the measured air dry bulb temperature by the devices and the free junction in the glass box at $4 \mathrm{~min}$ fog-on, $4 \mathrm{~min}$ fog-off, with $0.022 \mathrm{l} / \mathrm{min}$ fog rate.

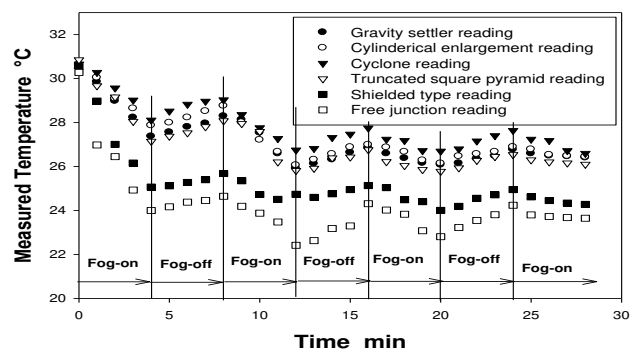

Fig. 14 Comparison between the measured air dry bulb temperature by the devices and the free junction in the glass box at $4 \mathrm{~min}$ fog-on, $4 \mathrm{~min}$ fog-off, with $0.033 \mathrm{l} / \mathrm{min}$ fog rate.

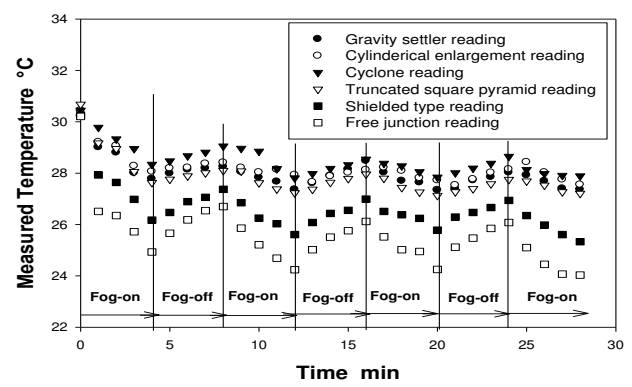

Fig.15 Comparison between the measured air dry bulb temperature by the devices and the free junction in the glass box at $4 \mathrm{~min}$ fog-on, $4 \mathrm{~min}$ fog-off, with $0.1 \mathrm{l} / \mathrm{min}$ fog rate.

\section{Effect of Decreasing the Cyclic Time}

Figures 16 to 18 illustrate the relation between the measured air dry bulb temperature by free and devices junctions under decreasing the cyclic time to $3 \mathrm{~min}$ fog-on then 3 min fog-off with fog flow rate of $0.022 \mathrm{l} / \mathrm{min}, 0.033 \mathrm{l} / \mathrm{min}$ and $0.1 \mathrm{l} / \mathrm{min}$ respectively. During the $3 \mathrm{~min}$ fog-on period the air temperature decreases in all devices and the air 
temperature inside the cyclone device is greater then any other device. Then came in order of lower temperature the cylindrical enlargement device, the gravity settler, the truncated square pyramid enlargement device, the conventional shielded device and finally the free junction which had the lowest air temperature. However, during the 3 min fog-off period the air temperature increased in all devices as is obtained in all experiments. The free junction always had the lowest air temperature, the devices behavior was the same in the remaining period of fog-on and fog-off periods. The data also showed that the maximum temperature difference between the cyclone device and the cylindrical device reached $1.3 \mathrm{C}$ but between the cyclone device and the free junction the difference reached $5.3 \mathrm{C}$.

For the same fog rate the difference of the indicated temperature by each device between the beginning and the end of the fog-on and fog-off periods in the latter cyclic $3 \mathrm{~min}$ fog-on, $3 \mathrm{~min}$ fog-off experiments was lower than in the previous cyclic 4 min fog-on, 4 min fog-off experiments.

The behavior of the free junction in the fog- on and in the fog- off periods is not satisfactory. If the measured temperature of the free junction is the reference of the fogging control system it would cause the fog to be terminated before its actual desirable time, because the free junction reading is lower than the actual air temperature in the fogged space. Also, it would cause the fog to be initiated after its actual desirable time, because the free junction reading is lower than the actual air temperature in the off-fogged periods. This causes an undesirable increase in the temperature of the air in the controlled medium.

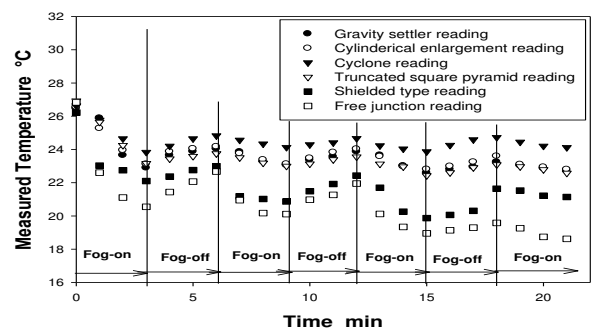

Fig. 16 Comparison between the measured air dry bulb temperature by the devices and the free junction in the glass box at $3 \mathrm{~min}$ fog-on, $3 \mathrm{~min}$ fog-off, with $0.022 \mathrm{l} / \mathrm{min}$ fog rate.

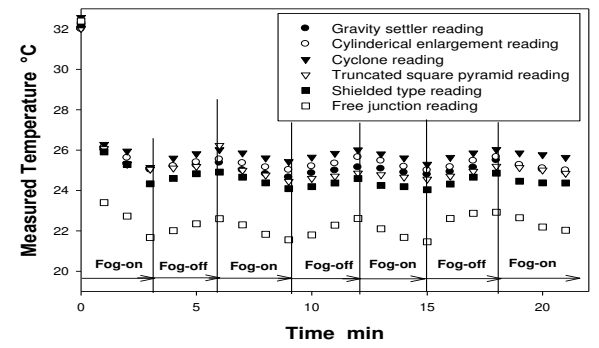

Fig. 17 Comparison between the measured air dry bulb temperature by the devices and the free junction in the glass box at $3 \mathrm{~min}$ fog-on, $3 \mathrm{~min}$ fog-off, with $0.033 \mathrm{l} / \mathrm{min}$ fog rate. 


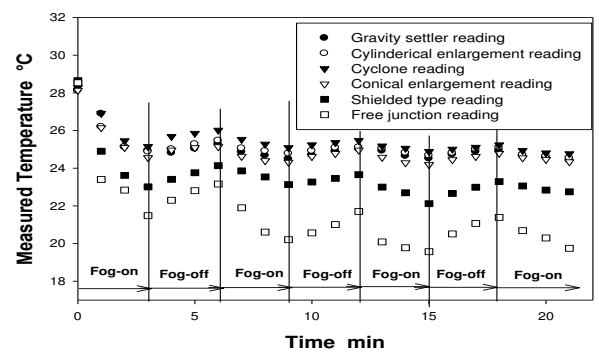

Fig. 18 Comparison between the measured air dry bulb temperature by the devices and the free junction in the glass box at $3 \mathrm{~min}$ fog-on, $3 \mathrm{~min}$ fog-off, with $0.1 \mathrm{l} / \mathrm{min}$ fog rate

\section{CONCLUSIONS}

The separating devices, especially the cyclone, give higher temperature, and hence better accuracy, than the free thermocouple junction which has always lower accuracy than that obtained by the separating devices. Also for high fog flow rates the cyclone device reading is close to the other separating devices because for the high fog rates the particles may be agglomerate into larger droplets which are easily separated by the other devices. Finally for any fog duration and flow rate, the rate of decrease of the indicated temperature increases largely at the beginning of fog-on period for higher initial temperature than for lower one.

\section{REFERENCES}

[1] H. Toida, K. Ohyama, T. Kozai, Handarto and M. Hayashi. 2006. A Method for measuring dry-bulb temperatures during the operation of a fog system for greenhouse cooling. Journal of Biosystems Engineering, 93 (3), 347-351.

[2] Yixing Li, Yuzhang Wang, Shilie Weng and Yonghong Wang. 2006. Development of a new temperature measuring system for gas-liquid flow in spraying field. Journal of Experimental Thermal and Fluid Science, (31), 917-924.

[3] Luc'ia Fern'andez Mart'inez, Antonio Guti'errez Lav'in, Manuel Mar'ia Mahamud and Julio L. Bueno. 2008. Vortex finder optimum length in hydrocyclone separation. Journal of Chemical Engineering and Processing, (47), 192-199.

[4] B. Wang and A.B. Yu. 2008. Numerical study of the gas-liquid-solid flow in hydrocyclones with different configuration of vortex finder. Journal of Chemical Engineering, (135), 33-42.

[5] L.R. Castilho and R.A.Medronho . 2000. A simple procedure for design and performance prediction of Bradley and Rietema hydrocyclones. Journal of Minerals Engineering. (13), 183-191

[6] B. Wang and A.B. Yu. Numerical study of particle-fluid flow in hydrocyclones with different body dimensions. Journal of Minerals Engineering. (19), 1022-1033.

[7] R. H. Perry, Don W. Green and James O. Maloney. 1997. PERRY'S CHEMICAL ENGINEERS' HANDBOOK. McGraw-Hill, 7th edition. 


\section{تصميم وتقييم أجهزة مختلفة لقياس درجة حرارة البصيلة

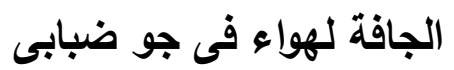

يستخدم التضبيب كثبرا فى نطبيقات مثل التبريد و الترطيب فى الصوبات الزجاجية وأبراج التبريد والمصانع وأنظمة التكييف. فى تبريد الصوبات الزجاجية يكون إستخدام نظام التضبيب (رش المياه فى الجو بضغط عالى)

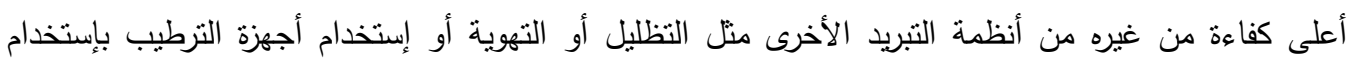

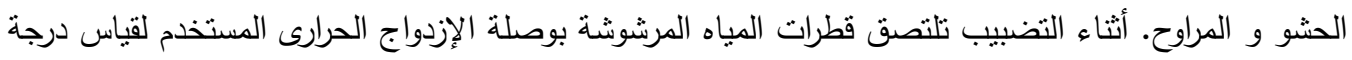

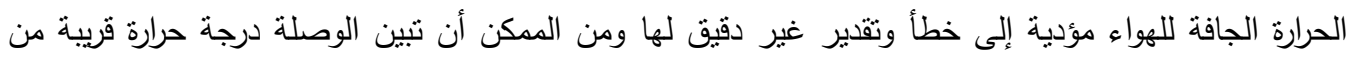
درجة حرارة البصيلة المبللة للهواء الرطب إذا تبخرت هذة القطرات الملتصقة بها. تقدم الدراسة الحالية طريقة لتقييم وقياس درجة حرارة الهواء الجافة فى ظروف التضبيب بشكل دقيق, و هذا التقييم تم بواسطة أستخدام إزدواج

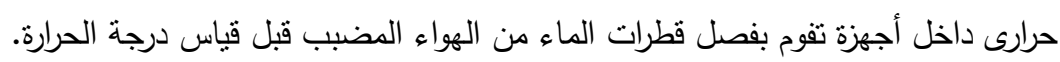

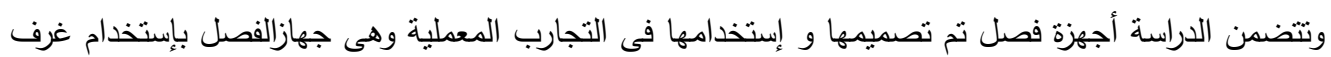
ترسيب قطيرات الضباب بالجاذبية والهرم المقطوع المقلوب ذو القاعدة المربعة والسيكلون و الإسطوانة الموسعة

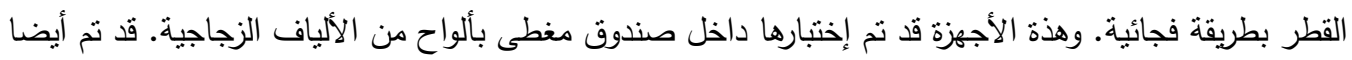

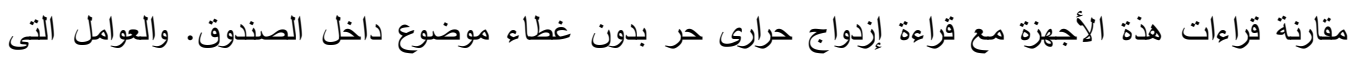

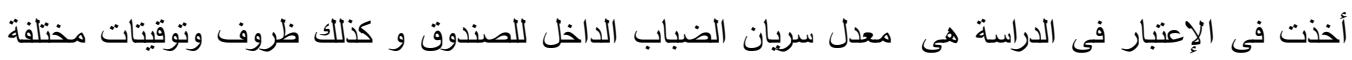
للتضبيب ووقت التضبيب.

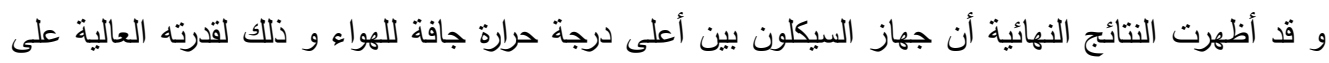

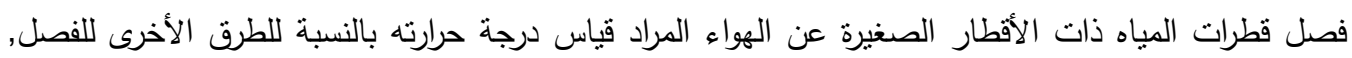

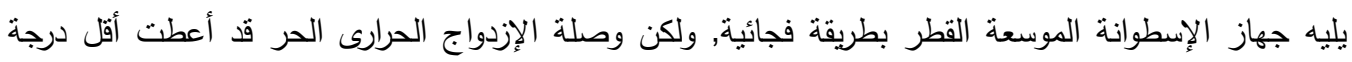
حرارة للهواء نتيجة التماس المباشر لها مع قطرات الضباب داخل الصندوق. و قد أظهرت الننائج النهائية أيضا

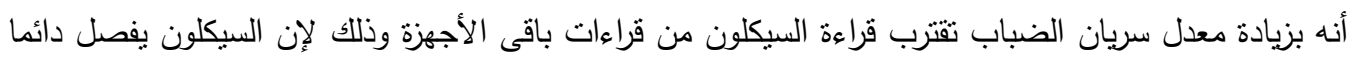

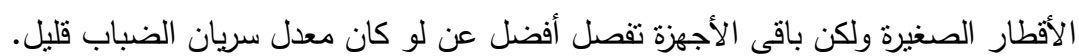

